\title{
Mathematical Instructional: A Conceptual of Redesign of Active Learning with Metacognitive Regulation Strategy
}

\author{
Mohamad Ariffin Abu Bakar
}

School of Education, Faculty of Social Sciences and Humanities, Universiti Teknologi Malaysia, Johor, Malaysia, mohamadariffin6299@ gmail.com

\section{Norulhuda Ismail}

School of Education, Faculty of Social Sciences and Humanities, Universiti Teknologi Malaysia, Johor, Malaysia, p-norulhuda@utm.my

$$
\begin{aligned}
& \text { Active Learning Strategy is a significant and effective learning approach to ensure } \\
& \text { student engagement in learning sessions and enhancing understanding of the } \\
& \text { contents. Active learning with high motivation and deep learning will encourage } \\
& \text { students to plan, monitor and to evaluate the learning process and manage thought } \\
& \text { activities. This metacognitive regulation ability will strengthen the student's } \\
& \text { understanding. Interacting skills, self-regulation skills, and excitement will increase } \\
& \text { and produce active experiences that positively impact the student's focus and } \\
& \text { actions during the learning process. Accordingly, Mathematical Metacognitive } \\
& \text { Activity (MMA) was developed with the concept of learning activities that } \\
& \text { incorporate active learning principles, strategies, and metacognitive regulation } \\
& \text { skills. Therefore, this conceptual paper discusses the potential of active learning to } \\
& \text { promote metacognitive regulation as a reinforcement of student understanding in } \\
& \text { the learning process. This study introduced and suggested the interventions of } \\
& \text { learning problems that is to increase the level of student's mastery in mathematical } \\
& \text { concepts. MMA is designed and developed based on the instructional development } \\
& \text { model, by applying the concept of active learning that involves collaborative } \\
& \text { metacognitive activities among students during the learning process. Through this } \\
& \text { activity, students will actively communicate and interact with peers to train } \\
& \text { metacognitive behavior and improve metacognitive skills to gain understanding } \\
& \text { and mastery of mathematical concepts. }
\end{aligned}
$$

Keywords: active learning, metacognitive strategies, student's mastery, mathematical learning, instructional setting

Citation: Abu Bakar, M. A., \& Ismail, N. (2020). Mathematical Instructional: A Conceptual of Redesign of Active Learning with Metacognitive Regulation Strategy. International Journal of Instruction, 13(3), 633-648. https://doi.org/10.29333/iji.2020.13343a 


\section{INTRODUCTION}

Mathematics is one of the complex subjects that students do not like (Chris, 2015; Hasbullah, 2015). The situations occur because of the low level of mathematical mastery and poor competency (Legg \& Locker, 2009). Although many efforts have been made to reduce the problem, it still cannot address the issue completely. Initiatives and interventions are implemented to motivate and build positive perceptions of students towards math (Legg \& Locker, 2009; Smith \& Mancy, 2018). But, it still cannot cover the weakness of the matter. The same aspect discussed is related to the mathematical knowledge itself which is abstract and requires a broader sense of thought (Hasbullah, 2015). Strength and ability to set the thinking is seen as one of the spins that influence the mastery of the students in mathematics. This situation is directly related to individual metacognitive capabilities. Studies by Leidinger \& Perels (2012), Hasbullah (2015), Listiani, Wiarta \& Darsana (2014), Nongtodu \& Bhutia (2017), Cheng (2011), Shaw (2008), Su, Ricci \& Mnatsakanian (2016), Stephanou \& Mpiontini (2017) and Idris, Abdullah \& Sembak (2015) have shown that metacognition greatly influence student performance and achievement.

Therefore, the metacognitive aspect is seen as the fundamental paths in this discussion. For a more in-depth assessment, the metacognitive component, metacognitive regulation, is a driving force in thinking and managing thoughts that affect learning (Phi, 2017). According to Schraw \& Moshman (1995), metacognitive regulation is an individual's ability to manage thinking in learning. When students are able to manage their thinking, they are able to use existing knowledge, plan and determine learning goals, monitor learning to achieve goals and evaluate how far the understanding is formed, it is also helpful in mastering the content of lessons (Schraw \& Moshman, 1995; Nelson \& Narens', 1990).

Therefore, teachers are encouraged to transact learning so that they can focus on the aspects of metacognitive regulation in planning the lessons. One of the effective learning approaches in developing metacognitive regulation is an active learning strategy as suggested by the constructivist experts (Rillero, 2016; Du Toit \& Du Toit, 2013). Through active learning strategies, students will be able to develop the real potential such us, self-regulation, self-belief and motivation in every mathematical learning to become meaningful (Listiani, Wiarta \& Darsana, 2014; Smith \& Mancy, 2018; Idris, Abdullah \& Sembak, 2015). During active learning, students will communicate and interact with peers. This will facilitate self-regulation especially the metacognitive aspects, to form the spirit of being active and engaging in learning (Moos \& Ringdal, 2012). Through active learning as well, students will be encouraged to force themselves to understand the learning requirements (Rillero, 2016). This is because, to stay active in learning, students should constantly monitor and evaluate their level of knowledge (Nelson \& Narens', 1990). A sense of self-esteem will come about if the student is successful to master the contents, but if not so good, it will form the spirit of continuing to explore and should also achieve the goals just like others (Tzohar-Rosen \& Kramarski, 2014). This situation will also lead to a coaching process, which will help and guide other peers (Raj, 2015). Pokhrel (2018) argued that the combination of active learning strategies, namely communication, metacognitive interaction, and regulation, 
will help in mathematical learning to ensure students can better master the mathematical concepts.

In the study by Sanip \& Ahmad (2014) for the biology subject, has shown that awareness of metacognition alone does not help students in mastery, especially when faced with high-level questions requiring Higher Order Thinking Skills (HOTS). In the mathematical contexts, this is because, which element that plays a role in mathematical learning is a metacognitive regulation that is more functioning to critical thinking skills (Tarricone, 2011). In line with suggestions by Smith \& Mancy (2018), teachers need to create collaborative metacognitive activities that can develop metacognitive regulation through the effects of interaction, so that students can master the lessons faster. Hence, further studies need to be undertaken to look at the needs, design and develop learning activities conceptualizing active learning strategies that will develop aspects of metacognitive regulation. Appropriate and interactive activities should be provided to enhance student achievement. Because of this, metacognitive regulation will be developed and trained when students engage and doing the activities. This situation can enhance and improve students' thinking and self-management skills. It can be emphasized that there is a need to design and develop activities that are compatible with the concept of active learning as well as metacognitive regulation skills. Further studies are needed to examine the relationship between learning activities and metacognitive learning strategies.

\section{Constructivism Perspective and Active Learning Views}

According to Constructivist Theory, learning is an active process, arranged and systematic, that explains the construction of the individual's meaning through a relevant previous experience (Magen Nagar, 2016; Ihdi Amin \& Sukestiyarno,2017) After that, they will respond and update to the experiences (Jones \& Araje, 2002). Constructivist Theory assumes that individual knowledge does not exist outside the mind, but is actively built in mind through real experience (Tzohar-Rosen \& Kramarski, 2014; Celik, 2018). According to Lam (2013), each individual builds knowledge through control of self-directed thinking during learning or beyond learning, which is when acquiring knowledge. Desoete \& Roeyers (2006) states that restructuring of cognition will occur during learning when a level of thinking is changing, in line with the acceptance of new knowledge and experience. Schraw \& Moshman (1995) said this cognitive structural change is a result of learning when students are exposed to experience. This cognitive transformation will only be known and realized by the individual itself, as a result of active action towards its learning (Bada \& Olusegun, 2015). Therefore, effective learning can derive from the process of layout and cognitive updates through an individual's active experience. There's the self-awareness of thinking and action to the situations of the thinking process (Lutz \& Huitt, 2004).

The ability and succes of building this cognitive structure illustrate the level of individual learning. The need for structural cognitive will be a burden that encourages and empowers individuals to learn during the learning process (Lutz \& Huitt, 2004). The relevance of previous knowledge and experience with current experience situations is a cognitive response process for acquiring new knowledge (Kaune, 2006). According to 
Nelson \& Narens' (1990), the previous, initial and next experience is also known as an individual metacognitive experience. It will be a link and boost factor in the learning process. Learning becomes meaningful when students are exposed to self-active experiences, 'by doing' through the minds-on and hands-on activities (Suriyon, Inprasitha, Sangaroon, 2013; Magen Nagar, 2016). Generally, learning will take effect according to the principles and processes of understanding the individual's intellectual tendency of knowledge processing. Caine \& Caine (1990) lists some of the principles based on cognitive and metacognitive learning processes. Mind and thinking can be expanded to create a natural and subconscious nature so that learning and development are compatible. This means that the need, the desire, and the diligence to explore learning should occur without exertion or compulsion from the outside, but it must happen through encouragement or self-regulation. This situation will open up the willingness and motivation of individuals to actively participate in learning (Caine \& Caine, 1990). To expedite the occurrence of this arrangement and encouragement, it requires a certain medium that is capable of attracting strength. This is where active learning strategies have discussed the need for scaffolding or mediators as a learning amplifier (Taylor, 1992). From here the various learning strategies to ensure students are actively involved in learning. Through the individual stage of development, cognitive development experts, according to Kaune (2006) and Daher, Anabousy \& Jabarin (2018), have suggested simulations or fun games is an ideal mediator based on the age level of students in primary or secondary school.

Ackerman \& Leiser (2014) have explained that gainer or scaffolding in learning depends on the level of students, where for higher-level students, their learning-driven is more to the goal or learning objective. While for lower-level students, the scaffolds are learning materials or learning situations. In short, the driven activity in learning is related to situations formed through an exciting source or goals. That way, in an active learning strategy, are required goals and the learning resources that can give a sense of motivation, cognitive and metacognitive effects. Based on the principle, Suriyon, Inprasitha, Sangaroon (2013) states that through active learning the students will have the opportunity to feel their own experiences, explore their view of problems and the information they have, always questioning, motivated, interesting and being fun. The effect of this active learning is not only on mastery but, even more depth is greatly influencing the development of metacognitive regulation skills. It's the effect of active learning physically and mentally which leads to the increase of the manipulative skills and metacognitive skills (Desoete \& Roeyers, 2006). In this context, there are some features of active learning according to Bada \& Olusegun (2015) which is to emphasize the excitement and interest during activities, can involve all students, can be followed by students, easy to understand the contents, learning by group and most importantly, to make sure the active involvement of students from the beginning to the end of the learning session.

\section{Active Learning Strategies to Promote Metacognitive Regulation}

Because of the nature of mathematics, as abstract sciences involving the relationship between the numbers, symbols, diagrams, patterns, forms, formulas and so forth (Chris, 
2015), mathematical learning requires appropriate strategies to achieve the learning objectives and the concept can be mastered. Mathematical mastery can be measured and viewed as a result when students can apply mathematical concepts and skills, especially when solving routine or non-routine problems.

According to Bonwell \& Eison (1991), through constructivist theory, John Dewey stressed that teachers carry out active learning as a process of updating, organizing or developing experiences continuously. Changes to the role of teachers and the functionality of the students are the main landscape of active learning based on constructivism. Tam (2000) has listed four basic features of an active learning environment based on constructivist theory, as a guide in planning active learning strategies: i) sharing knowledge together between teachers and students, ii) teacher and student sharing the authority, iii) teachers as facilitators and iv) learning activities through groups with small members and different levels of achievement.

In that regard, the intervention or the improvement of the approach should reflect the metacognitive development that reinforces thinking activities to understand the mathematical concept. Thus, an active learning strategy is the best choice. It coincides with the needs and requirements of mathematical learning aspects proposed by Abdullah, Rahman \& Hamzah (2017) which is based on metacognitive skills, critical thinking, inventive thinking and involving problem-solving. According to Schoenfeld (1992), mathematical learning requires change and innovation that transforms approaches by focusing on finding solutions and not just memorizing the working steps or operations, exploring patterns and formulas, and better in making predictive and wise in estimating. Based on the recommendations, it is evident that, developing metacognitive regulation through active learning is very important to ensure that mathematical learning coincided with the suggestions. This is because, in active learning, intelligent cognitive management is a matter of concern. Better and systematic cognitive management can improve thinking skills. According to Panaoura, Gagatsis \& Demetriou (2009), the situation is, increasing of metacognitive skills, which means that, when students can manage cognitive well based on the suitability of time or the right situation. Active learning is one of the supports to the students in formulating selfregulation especially in regulating metacognitive aspects.

Studies by Altintas \& Ozdemir (2012), Khan et al (2012), Hussain, Anwar \& Majoka (2011), Celik (2017), Khonchaiyaphum, Srikunlaya \& Rakrai (2017) and Yuksel (2013) has proven active learning through activities greatly influencing student learning and has a positive impact on student mastery. The researchers found that the effect of active learning on critical thinking skills and attitudes towards mathematical problem solving can be enhanced (Altintas \& Ozdemir, 2012). Inactive learning, students are more likely to think, criticize and ask questions. Active learning activities can expose students to discussions, debates, collaboratively in learning, and sharing opinions. These situations and actions will develop metacognitive skills. Accordingly, during active learning, in the first, students will be exposed to learning objectives or the aims of learning activities to be completed. Next, metacognitive planning aspects will be developed by students based on the goals to be achieved and previous knowledge. When actively doing tasks and 
activities, students will often ask questions, discuss, argue, guide and so on, when communicating and interacting with peers and teachers. This will encourage students to carry out their metacognitive monitoring. Next, throughout the tasks and activity, individually, students will always ask themselves the own level of learning, mastery, and understanding of the task or learning activities. At this time, the students have done their metacognitive evaluating. When students get better in planning, monitoring and evaluating, they have been increased metacognitive behavior and metacognitive skill, as known as a metacognitive regulation.

\section{METHOD}

The present study purpose of designing and developing mathematical learning activity, named Mathematical Metacognitive Activities (MMA). The aim of the study is also to evaluate the effectiveness of MMA on the student's learning. Therefore, the research question was formed to achieve the objectives:

1. What is the design and development of MMA based on a redesign of active learning with metacognitive regulation strategy?

2. What is the concept of the MMA that improves and affects students learning?

Based on the constructivist and metacognitive theories, some constructs are seen to influence student learning. The concept of learning based on constructivist theory is the process by which students adapt previous experiences and knowledge to new knowledge. Therefore, learning requires a specific medium or activity for this student's experience and knowledge to be reconstructed. In this regard, interaction, mediation, guidance, and scaffolding are important elements in the active learning model to show the potential of students in learning that also requires an environment for translation. Furthermore, metacognitive theory, states that metacognitive-based learning strategies can optimize students' mental functioning in the learning process. So a conceptual framework will be developed to look at the relationships between these constructs that will be the variables in this study.

\section{Conceptual Framework of Mathematical Metacognitive Activities (MMA)}

Applying active learning and ensuring metacognitive skills can be developed is a necessity in ensuring the teaching is more focused and meaningful, moreover, if a strategy is very useful for intervention purposes. However, a combination of active learning strategies and metacognitive regulation needs is an issue that requires a more practical solution. Therefore, this study through the conceptual framework developed will discuss how to blend the common criteria of learning activities, the concept of collaborative metacognitive activities and the active learning model proposed by Bonwell \& Eison.

\section{Common learning activities criteria}

The basic elements of producing learning activities must be met and can facilitate students to achieve learning objectives. According to Vygotsky's theory of development (Taylor, 1992), activity is a mediator to achieve learning objectives. Some criteria are defined in the form of activities, among them are intentional, meaningful and useful. The activities carried out must be in line with the objectives of the topic and learning 
outcomes. Therefore, the intent of the activity is then clear to both students and teachers. The aspects that are quite important in producing activities are meaningful and can ensure students develop and advance through learning. The activities that are built should not ignore existing knowledge and must be used in developing understanding, skills, and knowledge in different ways or through knowledge transformation. A meaningful activity will bind students to be active, constructive, authentic and cooperative.

Hence, useful learning activities will ensure students gain benefits through active involvement during activities and using knowledge for other contexts. However, this criterion is not a guide to be implemented when designing and operating activity, but thinking about the effectiveness and impact of activities on the student is more important in formulating the instruction. According to Nik Pa (1999), the role of mathematics teachers is as a provider of situations and activities relevant to the learning process. Such situations and activities can be a barrier, challenge, and problem for students to complete and encourage students if the activity is very realistic. According to Nik Pa (1999), through these activities, it is necessary to create two things: i) to activate certain mathematical schemes (existing knowledge) that the students have and ii) to ensure that students are involved in active and effective communication where students can reconstruct their mathematical knowledge schemes. This opinion is very consistent with the metacognitive processes outlined in metacognitive models (Schraw \& Moshman, 1995; Nelson \& Narens', 1990). The learning mechanism through this activity is an extension of the three-component model proposed by Piaget (Nik Pa, 1999).

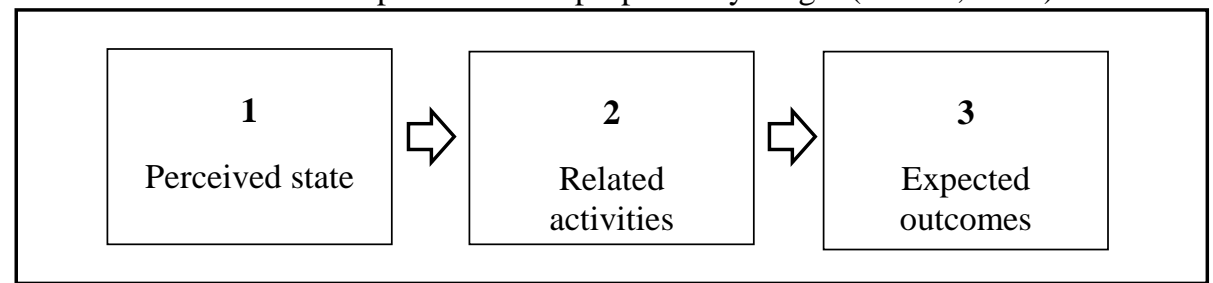

Figure 1

Piaget's Three-Component Model

\section{Smith \& Mancy Collaborative Metacognitive Activities Concept}

Smith \& Mancy (2018) has introduced the concept of Collaborative Metacognitive Activities which discusses how through group discussion activities can drive student learning performance. In any learning activity, a student will present the findings from collaborative discussions with friends and will deliver to the whole class. The role of explaining the student's content is entrusted to students with credibility and can attract other friends. According to Smith \& Mancy (2018), these selected students tend to influence peers to think the same way. The role of the student in communicating this lesson will affect the learning of other individuals. In the transactive concepts and mutuality listed, metacognitive talk is very effective to help students solve mathematical problems by comparing and sharing ideas. 


\section{Collaborative Metacognition}

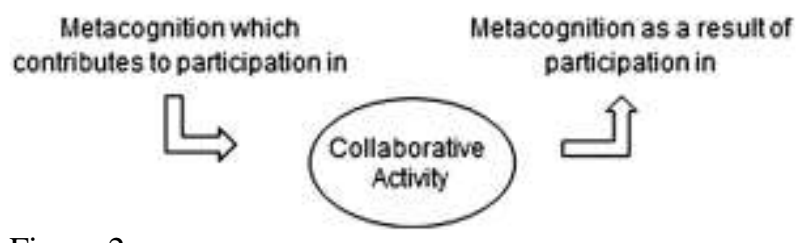

Figure 2

Demonstrated the Collaborative Metacognition Process (Smith \& Mancy, 2018)

During activities, interactions between students will form metacognitive interactions. The components of metacognitive regulation will act in their respective roles as speakers and listeners. This discussion activity will also meet the concept of collaborative metacognitive activities. The speaker will plan, set goals and targets. Next will always monitor the effectiveness of the presentation and will eventually reflect and evaluate the outcome of the effort. On behalf of the listener, planning and implementing prioritization needs, monitoring and ensuring that the content of the lesson is obtained and final evaluation of accuracy (Smith \& Mancy, 2018). In learning also, interactions between speakers and listeners will form metacognitive talk that will develop aspects of cognitive regulation.

\section{Bonwell \& Eison model of instruction}

To apply and produce active learning as an effort to transform the student's mathematical learning, Bonwell \& Eison (1991) outlined some of their features in their model

i. involves learning activities that enable students to develop their own potentials and skills which not only hear but also receive and transfer information

ii. students are encouraged to practice high-level thinking skills such as analysis, synthesis, and evaluation

iii. students will be more likely to explore their attitudes and self-values

Furthermore, through these guidelines seven elements of the model were formed to drive active learning namely, purposive; there is an association and achievement of objectives between learning and tasks, reflective; has characteristics that can be evaluated and achieved, negotiated; there is an opportunity between teachers and students to keep in discussion, critical; has an alternative or contingency aspect, complex; systematic and challenging tasks, situation-driven; situations and job environments that drive learning and engaged; will ensure students are actively involved. Concerning this, the principle of activity also directed to the development of metacognitive regulation through metacognitive learning strategies. According to Hasbullah (2015) activity is a medium or tool that can be a moderator of metacognitive regulation. In this context, Raj (2015) describes four principles of learning activities namely Experience, Reflection, Application, and Consolidation (ERAC), it is:

i. Experience: the initial stage of an activity, the term of experience symbolizes new experiences, new challenges, new environments gained through deep 
observation during the learning process and understanding the objectives of the topic and the students need to be ready to apply in the next topic or new situation (next learning).

ii. Reflection: is a self-assessment by thinking and giving insights into the impression of a new experience. The appreciation of the new experience will be more meaningful by the more focused questions on the effects and challenges that will be accepted.

iii. Application: at this stage students will apply the experience through a partnership with other students. Teachers are only acting as observers, providing only a little bit of guidance when needed, ensuring that students do activities according to the procedure and not formulating the findings. Students are given the opportunity to accept new terms with self-regulation first.

iv. Consolidation: The activity end step is a conciliation or conclusion. In this section, students should have achieved goals based on organizer and activity management. Here also can be used as a measure of how far the objectives of learning are achieved.

Applying and making this approach as a teaching and learning practice is essential to achieving effective learning goals. The features and principles of this practice are the concepts of active learning and metacognitive development. Through activities, students will evaluate and perceive knowledge from point of views, find similarities, evaluate causality, make predictions and estimates, not just remember and memorize and even take responsibility for new experiences and knowledge (Raj, 2015). This coincides with the recommendation by Su, Ricci \& Mnatsakanian (2015) which proposes a strategy that allows students to think, organize and coordinate their thinking to get good mathematical learning outcomes. Through this model, the previous knowledge and skills acquired by the students be a guide to create activities according to the current topic. The ultimate goal of the learning process is that students can modify the concepts to construct new math concepts and schemes. Teachers need to provide a learning environment that can increase student belief and potential. Teachers need to change the teaching paradigm and not be bound by traditional methods.

\section{Redesign of Active Learning with Metacognitive Regulation and Instructions MMA}

The concept of MMA is based on active learning strategies that can develop metacognitive aspects. According to Menz \& Cindy Xin (2016) and Hasbullah (2015), metacognitive skills can be improved through effective learning by applying active learning technique e.g problem solving, challenge-type or competition activities, presentation activities, etc. There is no one standard practice to implement theories in active learning. In this paper, all the theories are listed in Table 1, Elements reside in each theory are defined and understood by authors of the study as explained earlier in the same section of this article. Elements that have similar meanings and functions are grouped. In this paper a conceptual framework of MMA is proposed by merging Smith $\&$ Mancy collaborative metacognitive activities principles, Bonwell \& Eison model of instruction and common learning activity criteria. 
Table 1

Common Learning Activity, Concept of Collaborative Metacognitive and Bonwell \& Eison's Model of Instruction.

\begin{tabular}{lll}
\hline $\begin{array}{l}\text { Common learning } \\
\text { activity criteria }\end{array}$ & $\begin{array}{l}\text { Concept of collaborative } \\
\text { metacognitive activities }\end{array}$ & $\begin{array}{l}\text { Bonwell \& Eison's Model of } \\
\text { Instruction }\end{array}$ \\
\hline 1. Intentional & 1. Interactive & 1. Purposive \\
2. Meaningful & 2. Transactive & 2. Reflective \\
3. Useful & 3. Mutuality & 3. Negotiated \\
4. Experience & & 4. Critical \\
5. Reflection & & 5. Complex \\
6. Application & & 6. Situation-driven \\
7. Consolidation & & 7. Engaged \\
\hline
\end{tabular}

The framework is proposed due to an increase in research interest in active learning and metacognitive strategies. At the same time, there is a limited existing framework in MMA, especially in Mathematics subjects. In this paper, the proposed framework is known as the Conceptual Framework of Mathematical Metacognitive Activities (MMA). Figure 3 represents the general concept of the conceptual framework. The proposed framework consists of four interrelated components. It is believed the integration of these components would optimize learning, develop metacognitive skills and enhance students' mastery.

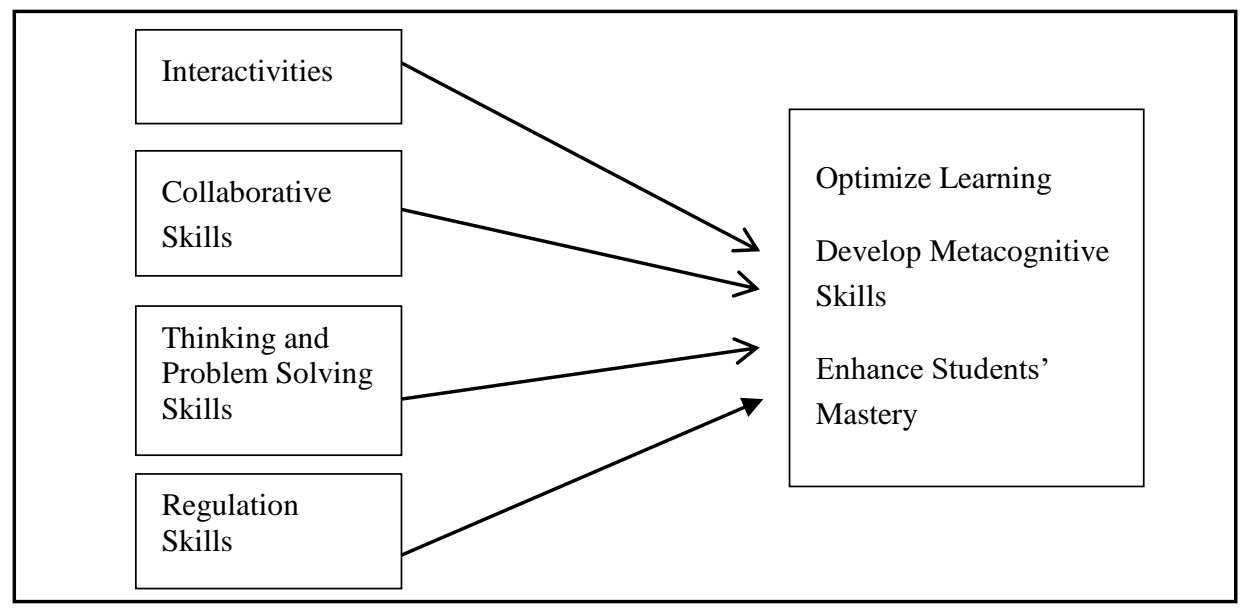

Figure 3

Conceptual Framework of MMA

\section{Interactivities}

Activity is a stimulus medium to the student's previous experience. Activities are transformed into a field to structure existing knowledge and experience by modifying to create new knowledge or skills. The activity must expose students to minds-on and hands-on experience (Celik, 2018). According to Nik Pa (1999) activity is a relevant situation to shape the action of knowledge schemes. Critical reflection action after the 
activity is seen as a restructuring of a particular scheme or concept. This activity should also provide opportunities for all parties involved to equally assess and reflect on their own. The learning activity can be considered as a metacognitive strategy in which metacognitive capabilities and actions can be developed and emphasized (Schraw \& Moshman, 1995). Through activities, it not only creates awareness of cognitive structures but also creates cognitive regulation to improve thinking skills in terms of mastering the content of the lesson.

\section{Collaborative skill}

It is the component that forms the learning environment. Students will communicate and interact individually or in groups. These interactions have multiple levels, namely students with learning materials, students with self (cognitive), students with students and student interaction with teachers (Kozulin, 2004). In fact, according to the constructivism perspective, social interaction is very important, because through interaction (individually) previous and prior knowledge will form meaningful learning. The social interactions with other groups and individuals will influence the construction of meaning by students. According to the metacognitive theory, during the interaction, the students will feel worried and there will be anxiety over their learning outcomes with others (Pantiwati \& Husamah, 2017). This situation will trigger metacognitive awareness and then the student will take cognitive action (metacognitive regulation) to ensure that he/she can achieve the goal or learning objectives (Taylor, 1992). Accordingly, collaborative skills can instantly develop interpersonal skills such as tolerance, ability to listen and accept dissent (Daher, Anabousy \& Jabarin, 2018). This collaborative activity and skills trigger learning through discovery by understanding the feelings, attitudes, and values of peers. Even from the mathematical context, students can find out the solution strategies that peers use. This can stimulate the reflection of actions that lead to the formation of cognitive regulation. The self-evaluation will form the urge to learn.

\section{Thinking and problem solving skills}

The next component that should be contained in learning activities is thinking skills and the ability to solve mathematical problems well, based on metacognitive learning strategies that prioritize the effectiveness of cognitive thinking and capabilities. According to Hasbullah (2015), a metacognitive strategy approach must contain dimensions of promoting awareness and cognitive actions such as problem-solving, challenge-type or competition activities, presentation activities and so on. Phases in learning activities, especially in the climactic phase of the activity, require students to think and act on the right strategy. Thinking skills can be improved and this will influence student learning efforts and actions. MMA also features learning through real experience. Because learning is an experience inherent to all individuals, so the framework of thinking concerning experience exists and the assimilation process in the constructivist view is more readily in their minds ( $\mathrm{Nik} \mathrm{Pa}, 1999)$.

\section{Regulation skills}

According to Hasbullah (2015) and Smith \& Mancy (2018) when learning activities that require students to plan, setting goals and targets, acting on their planning strategies and 
constantly evaluating learning acquisitions, are related to metacognitive regulation skills. This process can improve regulation skills and drive awareness and thinking actions. Therefore, this skill must be present in MMA as a component that can improve the mastery of the students. Regulations are also a necessity because, with effective learning management, students are aware of resources, aware of strengths and weaknesses, know how to avoid mistakes and keep track of achievements. This skill helps students to manage to learn while performing their activities.

\section{DISCUSSION}

Based on the above framework, it can be concluded that MMA modified active learning strategies when focused on improving students' metacognitive skills. This is because active learning provides only physical evidence that students are engaged and involved in the learning process. The students also show interest and enjoyment of learning, but the deeper concept of MMA will ensure that students can develop their learning frameworks or models to enhance learning effectiveness. The point here is that MMA is a medium for ensuring that mental processes occur during the learning process. According to Nik Pa (1999), mental models occur when students use thinking skills and formulate knowledge frameworks as temporary models or early representations of mathematical concepts being studied. However, this framework will be restructured when students can manage their cognitive functions and develop lasting knowledge during learning through metacognitive regulation capabilities.

Gartmann \& Freiberg (2017) and Smith \& Mancy (2018) state that, learning through activities, where students need to plan, set goals and objectives, act on what they have planned and need to evaluate learning outcomes, they are in a metacognitive regulation stage. This process enhances students' thinking skills and potential. In conclusion, through the activities implemented, it has a positive impact on the students. The effect of learning through activities enhances interaction and discussion effectively, creates opportunities for mentoring and also promotes collaborative skills where students can actively engage and contribute to quality learning (Celik, 2018; Festus, 2013). It can be seen that activity as a medium for students to develop many skills that will contribute to increased mastery of the mathematical concepts learned. According to Schraw \& Moshman (1995) and Kaune (2016), current learning activities will train and enhance the skills of planning, monitoring and evaluating learning processes. These metacognitive skills can be enhanced through student self-control which can also influence students' attitudes and motivation towards mathematics. Previous experience and active experience during activity can be well organized. Besides, according to Pantiwati \& Husamah (2017) and Menz \& Cindy Xin (2016) activities can also be used as instruments for learning assessment. This evaluation can be either independent or self-contained (Menz \& Cindy Xin, 2018) or through interaction during activities (Pantiwati \& Husamah, 2017).

Implementing this approach as best practice in teaching and learning is highly recommended to produce effective learning. The concepts and principles of MMA are from the concept of active learning and the development of metacognitive skills. When students are constantly exposed to cooperative or collaborative learning, they will 
communicate and interact with peers. Math problems are made easier when they are guided by self-directed learning along with their intellectual potential and creative minds. This intellectual ability will be enhanced and strengthened when students master new concepts and skills. This process will be repeated in the next lesson and will help the mastery of students' mathematical concepts.

\section{CONCLUSION}

As a conclusion, it can be seen that effective mathematical learning can improve the mastery of the students and also to establish self-determination, self-belief, and selfregulation of the students. To improve the effectiveness of learning is through the learning environment that can attract and encourage the active involvement of the students. Mathematical learning needs an interesting medium that can be exciting to students. It also can give chance to the development of metacognitive skills and thinking skills in line with the natural characteristic of mathematics, as abstract sciences and should be exposed to thinking activities likes reasoning. Therefore, the research and contribution of this concept paper are very suitable to be used as a suggestion to the problem of mastery of the students towards mathematics. It is also a guide for subsequent researchers in studies the strategies or effectiveness of mathematical learning, especially using models or theories that have been used in the present study.

Learning models can be developed based on these suggestions that will implement students' metacognitive skills. Also, through this study, learning modules can be created that include interactive activities that can enhance students' engagement and enjoyment of their mathematical teaching.

\section{REFERENCES}

Abdullah, A. H., Rahman, S. N. S. A., \& Hamzah, M. H. (2017). Metacognitive skills of Malaysian students in non-routine mathematical problem solving. Bolema, Rio Claro (SP), 31(57), 310-322. http://dx.doi.org/10.1590/1980-4415v31n57a15.

Ackerman, R., \& Goldsmith, M. (2011). Metacognitive regulation of text learning: On Screen versus on paper. Journal of Experimental Psychology: Applied, 17(1), 8-32. Doi:10.1037/a0022086.

Ackerman, R., \& Leiser, D. (2014). The effect of concrete supplements on metacognitive regulation during learning and open-book test taking. British Journal of Educational Psychology, 84(2), 329-348.

Altintas, E., \& Ozdemir, A. S. (2012). The effect of teaching with the mathematics activity based on purdue model on critical thinking skills and mathematics problem solving attitudes of gifted and non-gifted students. Pro-Soc and Beha Sci, 46, 853-857.

Amin, I., \& Sukestiyarno, Y. L. (2015). Analysis of metacognitive skills on learning mathematics in high school. Int Journal of Education and Research, 3(3), 213-222.

Bada, \& Olusegun, S. (2015). Constructivism learning theory: A paradigm for teaching and learning. IOSR-JRME, 5(6), 66-70. Doi: 10.9790/7388-05616670.

Bonwell, C. C., \& Eison, J. A. (1991). Active learning: creating excitement in the classroom. ERIC Digest. ERIC Clearinghouse on Higher Education. Washington DC. 
Caine, R. N., \& Caine, G. (1990). Understanding a brain-based approach to learning and teaching. Association for Supervision and Curriculum Development, National Education Service. Bloomington.

Celik, H. C. (2018). The effects of activity based learning on sixth grade students' achievement and attitudes towards mathematics activities. EURASIA Journal of Mathematics, Science and Technology Education, 2018, 14(5), 1963-1977.

Cera, R., Mancini, M., \& Antonietti, A. (2013). Relationship between metacognition, self-efficacy and self-regulation in learning. ECPS-Journal, 7, 116-141. doi:10.7358/ecps-2013-007-cera.

Cheng, E. C. K. (2011). The role of self-regulated learning in enhancing learning performance. The International Journal of Research and Review, 6(1), 1-16.

Chris, O. (2016 March, 14). Teaching math in the 21st century. Changing the focus from calculations to critical thinking. Retrieved from http://blog.learningbird.com.

Daher, W., Anabousy, A., \& Jabarin, R. (2018). Metacognition, positioning and emotions in mathematical activities. International Journal of Research in Education and Science (IJRES), 4(1), 292-303. Doi:10.21890/ijres.383184.

Desoete, A., \& Roeyers, H. (2006). Metacognitive macro evaluations in mathematical problem solving. Lear and Inst, 16, 12-25. doi:10.1016/j.learninstruc.2005.12.003.

Du Toit, S. D., \& Du Toit, G. F. (2013). Learner metacognition and mathematics achievement during problem-solving in a mathematics classroom. TD The Journal for Transdisciplinary Research in Southern Africa, 9(3), Special edition, 505-518.

Gartmann, S., \& Freiberg, M. (1998). Metacognition and mathematical problem solving: Helping students to ask the right questions. The Math Educator, 6(1), 9-13.

Hasbullah. (2015). The Effect of ideal metacognitif strategy on achievement in mathematics. Int J of Edu Res Tec, 6(4), 42-45. Doi:10.15515/ijert.0976-4089.6.4.4245.

Hussain, S., Anwar, S., \& Majoka, M. I. (2011). Effect of peer group activity-based learning on students' academic achievement in physics at secondary level. International Journal of Academic Research, 3(1), 940-944.

Idris, N., Abdullah, N., \& Sembak, S. (2015). Metacognitive awareness and conceptual understanding in mathematical problem solving. Malay J of Sci \& Math, 5(2), 23-40.

Jones, M. G., \& Araje, L. B. (2002). The impact of constructivism on education: Language, discourse, and meaning. American Communication Journal, 5(3).

Kaune, C. (2006). Reflection and metacognition in mathematics education-tools for the improvement of teaching quality. ZDM, 38(4), 350-360.

Khan, M., Muhammad, N., Ahmed, M., Saeed, F., \& Khan, S. A. (2012). Impact of activity-based teaching on students' academic achievements in physics at secondary level. Academic Research International, 3(1), 146-156.

Khonchaiyaphum, P., Srikunlaya, S., \& Rakrai, W. (2017). Development of activitybased learning conceptual approach with the stem education instructional method on the 
photosynthesis issue at the 11th grade level to promote students' learning achievements and their systematic thinking abilities. European J of Education Studies, 3(6), 466-484.

Kozulin, A. (2004). Vygotsky's theory in the classroom: Introduction. European Journal of Psychology of Education, XIX(I), 3-7.

Lam, B. H. (2013). Constructivist learning and teaching. Hong Kong: HKU Press.

Legg, A. M., \& Locker, L. (2009). Math performance and its relationship to math anxiety and metacognition. North American Journal of Psychology, 11(3), 471-486

Leidinger, M., \& Perels, F. (2012). Training self-regulated learning in the classroom: Development and evaluation of learning materials to train self-regulated learning during regular mathematics lessons at primary school. Hindawi Publishing Corporation Education Research International, 2012, 735790. doi:10.1155/2012/735790.

Listiani, N. W., Wiarta, I. W., \& Darsana, I. W. (2014). Implementation of openproblems-based metacognitive learning models on students mathematics learning outcomes kelas v sd gugus 8 blahbatuh. Jurnal Mimbar PGSD Universitas Pendidikan Ganesha, 2(1).

Lutz, S., \& Huitt, W. (2004). Connecting cognitive development and constructivism: Implications from theory for instruction and assessment. Cons in the H Sci, 9(1), 67-90.

Magen Nagar, N. (2016). The effects of learning strategies on mathematical literacy: A comparison between lower and higher achieving countries. IJRES, 2(2), 306-321.

Menz, P., \& Cindy, X. (2016). Making students' metacognitive knowledge visible through reflective writing in a mathematics-for-teachers course. Collected Essays on Learning and Teaching, IX, 155-166.

Moos, D. C., \& Ringdal, A. (2012). Self-regulated learning in the classroom: A literature review on the teacher's role. Education Research International, 2012, 423284.

Nongtodu, S., \& Bhutia, Y. (2017). Metacognition and its relation with academic achievement among college going students of Meghalaya. International Journal of Education and Psychological Research (IJEPR), 6(2), 54-60.

Nelson, T. O., \& Narens, L. (1990). Metamemory: A theoretical framework and new findings. Psychology of Learning and Motivation, 26, 125-173.

Nik Pa, N. A. (1999). Radical constructivism approaches in mathematics education. Kuala Lumpur: Universiti Malaya Publisher.

Pantiwati, Y., \& Husamah. (2017). Self and peer assessments in active learning model to increase metacognitive awareness and cognitive abilities. International Journal of Instruction, 10(4), 185-202.https://doi.org/10.12973/iji.2017.10411.

Panaoura, A., Gagatsis, A., \& Demetriou, A. (2009). An intervention to the metacognitive performance: Self-regulation in mathematics and mathematical modeling. Acta Didactica Universitatis Comenianae Mathematics, 9, 63-79.

Phi Van Thuy. (2017). Developing students metacognitive skills in mathematics classroom. Annals. Computer Science Series, XV(1), 41-46. 
Pokhrel, T. R. (2018). Activity based mathematics instruction: Experiences in addressing the 21st-century skills. Journal of Mathematics Education, 11(1), 46-61.

Raj, M. B. (2015). The effectiveness of activity based learning: An analysis. Veda's Journal of English Language and Literature-JOELL, 2(4), 84-87.

Rillero, P. (2016). Deep conceptual learning in science and mathematics: Perspectives of teachers and administrators. Electronic Journal of Science Education, 20(2), 14-31.

Sanip, F. A., \& Ahmad, C. N. (2014). Metacognitive awareness strategies and high order thinking skills (HOTS) among biology students. J Penye Pendi (KPM) Jilid 15.

Schoenfeld, A. H. (1992). Learning to think mathematically: Problem solving, metacognition, and sense-making in mathematics. In D. Grouws (Ed.), Handbook for research on mathematics teaching and learning (pp. 334-370). New York: MacMillan.

Schraw, G., \& Moshman, D. (1995). Metacognitive theories. Educational Psychology Review,7(4), 351-371.

Shaw, S. C. (2008). The effects of metacognitive awareness on the development of mathematical problem-solving skills in fourth-grade homework assignments (Unpublished doctoral dissertation). Western Connecticut State University.

Smith, J. M., \& Mancy, R. (2018). Exploring the relationship between metacognitive and collaborative talk during group mathematical problem solving-what do we mean by collaborative metacognition? Research in Mathematics Education, 20(1), 14-36. Doi:10.1080/14794802.2017.1410215.

Stephanou, G., \& Mpiontini, M. (2017). Metacognitive knowledge and metacognitive regulation in self-regulatory learning style, and in its effects on performance expectation and subsequent performance across diverse school subjects. Psychology, 8, 1941-1975. https://doi.org/10.4236/psych.2017.812125.

Su, H. F., Ricci, F. A., \& Mnatsakanian, M. (2016). Mathematical teaching strategies: Pathways to critical thinking and metacognition. J of Res in Edu and Sci, 2(1), 190-200.

Suriyon, A., Inprasitha, M., \& Sangaroon, K. (2013). Students' metacognitive strategies in the mathematics classroom using open approach. Psychology, 4(7), 585-591.

Tam, M. (2000). Constructivism, instructional design and technology: Implications for transforming distance learning. Educational Technology \& Society, 3(2), 50-60.

Tarricone, P. (2011). The taxonomy of metacognition. New York: Psychology Press.

Taylor, L. (1992). Mathematical attitude development from a Vygotskian perspective. Mathematics Education Research Journal, 4(3), 8-23.

Tzohar-Rosen, M., \& Kramarski, B. (2014). Metacognition, motivation and emotions: Contribution of self-regulated learning to solving mathematical problems. Global Education Review, 1(4), 76-95.

Yuksel, I. (2013). Impact of activity-based mathematics instruction on students with different prior knowledge and reading abilities. Int J of Sci \& Math Edu, 12, 1445-1468. 